\title{
Biomechanical Determiner as a Basis for Suggesting some Qualitative Exercises for the Skill of Drop on the Heels in Free Wrestling
}

*Dr/ Osama El-sayed Tmmam

Introduction and Problem of the Research

There is a notable difference between the skill level practiced by the players to achieve a certain goal according to the concepts that existed at the time and the developed skills, as reflected directly on the levels achieved by players in different tournaments.

Mossad Ali Mahmoud (2005) stated that the development of modern wrestling technique is based on the principles of bio-mechanics as well as the design of a group of "tactical" formations for wrestling. (9: 76)

Through the experiences of the researcher and his work as a first referee of the wrestling in the Egyptian Federation of wrestling and through reading some scientific references and previous studies(1), (2), (3), (4), (5), (6), (7), (8), (10), (11), (12), (13), (14), (15), it has been shown that most wrestlers, during practicing the skill of Drop on heels are subject to failure and this may be due to the lack of training on some exercises that correspond to the specified motor track of the skill performance or may be due to the lack of experience of their trainers or the paucity of sufficient theoretical applied information for the skill perfection under study. This may affects the level of performance of many players, although the law emphasizes the skill the study dealt with, where specifies four (4) for the successful performance as well as gives the attacker the opportunity to achieve the touch of the shoulders.

The researcher conducted a survey on the referees of the Egyptian Federation of wrestling through the personal interview with many of them during the course of the final promotion of the referees located at the Faculty of

"Lecturer of Biomechanics- Wrestling in Department of Sports Training and Movement Science Faculty of Physical Education Assiut University 
Physical Education for Girls at Alexandria University. The researcher resulted, through showing a series of inquiries to some international referees, the importance of skill where it makes the game in many times finish if it is completed quickly and accurately and also what happened in the recent amendments to international law of wrestling, especially fight against the negative, increases the importance of skill where making the game in a constant conflict without interruption.

To the knowledge of the researcher that there is a rare in the research which dealt with the analysis of the form of performance in the sport of free wrestling and the skill of Drop on heels has not been subjected to any detailed study, despite its importance to all wrestlers without exception, which prompted the researcher to study the problem of research represented in identifying the most important mechanical variables of skill under study.

\section{Research Goals}

This research aims to:
- Identify the quantitative determinant the skill of Drop on heels on the model player.

- Put a set of qualitative exercises according to the mechanical determinants of the skill being studied.

\section{Research questions}

- What is the quantitative determinant of the skill of Drop on heels the model player model?

- What are the qualitative exercises of the skill of Drop on heels for the free wrestling players?

\section{Research Methodology}

The researcher used the descriptive method (case study) through the kinetic analysis of the performance of the skill in question in order to its suit to the nature and goals of the research.

\section{Research community}

The research community is represented by the players of the Egyptian Federation, Asyut branch (Assiut area) in the sport of free wrestling.

\section{Sample Search}

The research sample was chosen in a deliberate manner, represented in the model player from the Egyptian team for wrestling who distinguished in 
the performance the skill of Drop on heels.

\section{Data collection tools}

- Two-dimensional Simi unit for motor analysis, (Attachment2).

- Medical balance to measure weight in kilograms.

- Resistometer to measure length (centimeter)

- Stopwatch to measure time.

- Legal wrestling training mat $12 \mathrm{~m} \times 12 \mathrm{~m}$.

- Calibration Unit $2 \mathrm{~m}$ x $2 \mathrm{~m}$.

Meter Measurement tape:Used Statistical processors

The researcher used the following statistical methods: -Estimated grade.

- Percentage

\section{Discussing the results}

In light of the research objectives, and answering its questions, the researchers deal with the results obtained and discussed through the statistical processors of the data obtained, as follows:

- What is the quantitative determinant the skill of Drop on heels for the player model?

- What are the qualitative exercises the skill of Drop on heels for the free wrestling players?

Discussing the results of the first question

- What is the quantitative determinant of the skill of Drop on heels to the top of the player?

- The results of the kinetic analysis the skill of Drop on heels for the player (sample of the research)
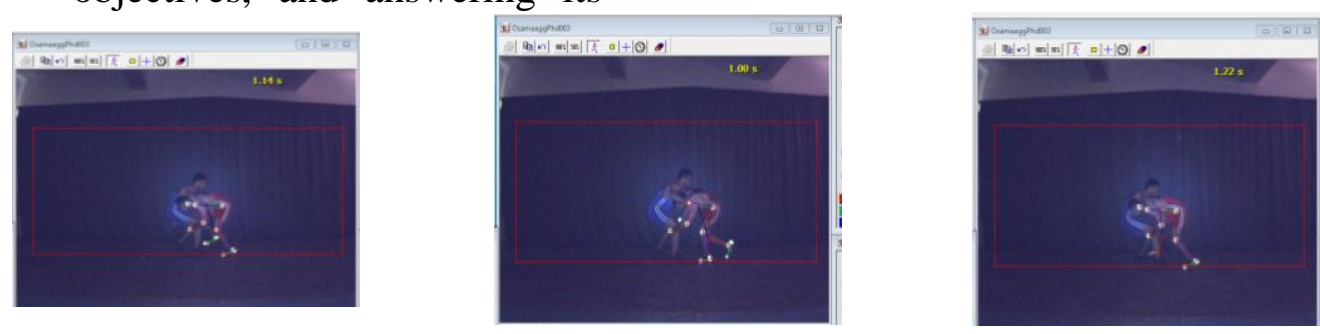

Assiut Journal For Sport Science Arts 


\section{1}
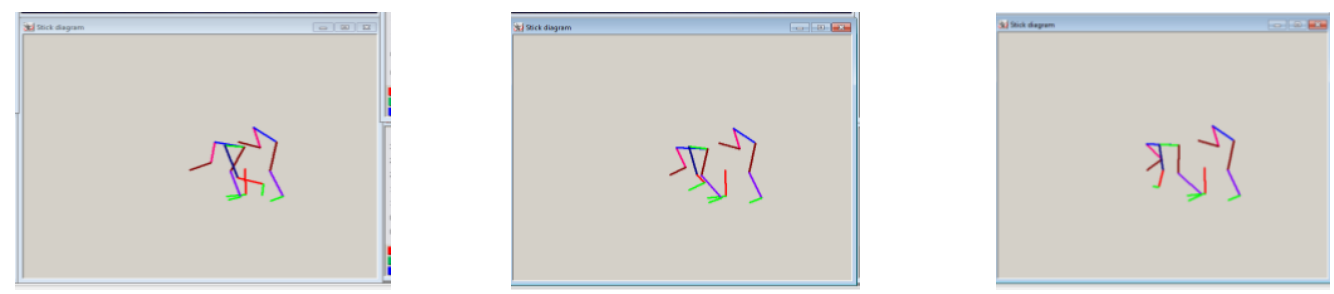

Figure (1) Characteristic description of the skill of Drop on heels

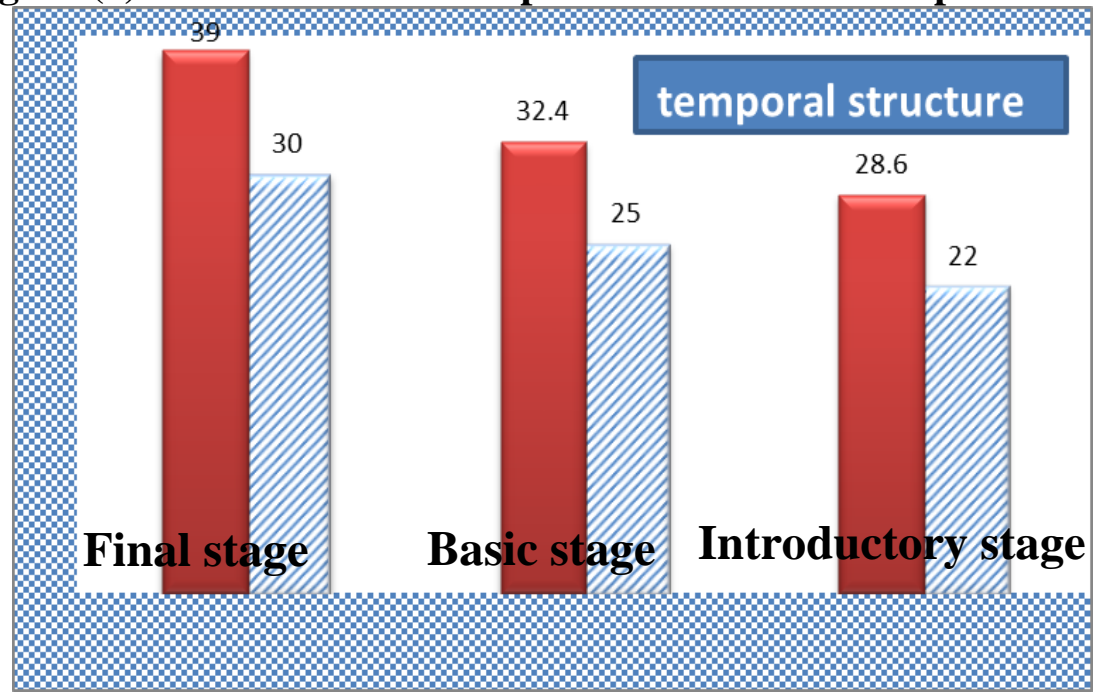

Figure (2) The temporal structure of the skill of Drop on heels

The temporal structure shape description were shown in Figure (1) and (2) where he total time the skill of Drop on heels was (1.17 seconds), the time of the introductory stage (hold and aggregation) was
0.22 and the percentage was 28.6\%, (Throwing and implementation ) $\quad 0.25$ percentage point was $32.4 \%$, and the time of final stage (imprisonment) was 0.30 and the percentage was $39 \%$ 
Table (1)

Linear and angular variables for the skill of Drop on the heel in the sport of free wrestling for the preliminary stage (hold and accumulation) 
Table (1) shows the following

The right heel was the largest displacement part in the hold and accumulation stage of the skill of Drop on the heel, where the total displacement was $(1.416 \mathrm{~m})$. While the right pelvis was the lowest displacement part of the body with a value of $0.643 \mathrm{~m}$. The right heel was the largest speed part in the hold and accumulation stage of the skill of Drop on the heels with a value of $5.961 \mathrm{~m} / \mathrm{s}$, while the left foot was the lowest of the body parts with a speed of $0.063 \mathrm{~m} / \mathrm{s}$. The right heel was the fastest part of the body in the hold and accumulation stage of the skill of Drop on the heel, which was $(30.020 \mathrm{~m} / \mathrm{s})$, while the right foot was slowest part which was $(-21.323 \mathrm{~m} / \mathrm{s})$. The difference between the angles has a scientific evidence, where the left angles values of the left shoulder were (64.624), the left pelvis (78.963), the left heel (75.084), the right heel (75.980) with acute angle values. While the angles values of the left elbow were (94.575) and the left knee (128.007) and the right knee (153.360) with the different angles of the diffraction.

The angular speed of the body parts in the hold and accumulation stage varied, where the highest was the right knee with a value of (1329.016 $\varnothing / S)$ and the lowest was the left heel with a value of (60.390 Ø / S). It has been shown that the angular change in the acceleration of the body parts also varied, which its highest value was the right heel with a value of (10796.433 Ø / $2 \mathrm{~S})$ and the lowest was left knee which reached (-1219.728 $\varnothing / 2 S)$. 
Table (2)

Linear and angular variables for the skill of Drop on the heel in the sport of free (basic stage) 
Table (2) shows the following

The right heel was the largest displacement part in the stage of implementation and throwing of the skill of Drop on the heel, where the total displacement was $(2.052 \mathrm{~m})$, while the left foot was the lowest displacement part of the body with a displacement value of $0.681 \mathrm{~m}$. The left elbow was the largest speed part in the stage of throwing and implementation of the skill of Drop on the heel, where the total speed was $(3.391 \mathrm{~m} / \mathrm{s})$, while the left foot was the lowest speed part reaching the result of speed $(0.369 \mathrm{~m} / \mathrm{s})$

The left heel was the fastest part of the body in the stage of throwing and implementation of the skill of Drop on the heel, where the result of the accelerate was (20.439 m / s 2), while the right foot was the slowest part of the body where the result of the accelerate (- $76.806 \mathrm{~m} / \mathrm{s} 2)$.
The difference between the angles has a scientific evidence, where the values of angles of the left shoulder was (8.946), the left elbow (88.248), the left heel (72.202), the right heel (57.768) with values of acute angle, and angles values of left pelvis were (127.890) ), the left knee (155.170), the right knee (141.419) with the different angles of the diffraction. The angular speed of the body parts in the stage of throwing and implementation varied, the largest being the left shoulder which was (- 1084.021 Ø/S) and the lowest value was the left shoulder which its angular speed was(- $14.723 \varnothing / S)$. It is also shown that the value of angular acceleration of the body parts varied which its highest value the right shoulder (225974.094 Ø/2S) and the lowest value was the right heel (- 112,319.883 Ø / 2S). 
Table (3)

Linear and angular variables for the skill of Drop on the heel in the sport of free wrestling for final stage (confinement) 
Table (3) shows the following

The left heel was the largest displacement part of the body in the confinement stage of the skill of Drop on the heel, which the result of the displacement was $2.470 \mathrm{~m}$, while the left foot was the lowest displacement part .The left wrist was the fastest part in the confinement stage of the skill of Drop on the heel. The total speed was $6.302 \mathrm{~m} / \mathrm{s}$, while the left knee was the slowest part at a speed of $1.418 \mathrm{~m} / \mathrm{s}$. The left elbow was the fastest body parts in the confinement stage of the skill of Drop on the heel, which reached $43.825 \mathrm{~m} /$ s2, while the left pelvis was the slowest part of the body which the acceleration reached (15.184 m/s).

Table (3) shows that the angles in the confinement stage took two forms where the angles of the elbow, shoulder, knee and heel were acute angles while the angle of the thigh took the sporadic shape. As shown in Table (3) the values of the angular change of the speed in the confinement stage varied, where its highest value was of the left heel with 1035.267, and the lowest one was the left shoulder with (627.803).

where the values of change of angular speed in each of thigh, elbow and shoulder took the minus signal. As well as, the table 3 shows that the value of angular change in acceleration in confinement stage varied and the fastest part was the left heel with a value of (65709.297), and the lowest was the left shoulder with (-16793.752) and the values of change in the angular acceleration in both the thigh and shoulder were decreasing as they took the minus signal.

Presentation and discussion of the results of the second question:

- What are the qualitative exercises for the skill of Drop on the heel for free wrestling players?

- After presenting the results of the researcher, and through used statistical processors, and the previous studies and the latest scientific references, the researcher has presented the results of the third question, and was answered by the researcher through the procedural steps of the opinions of experts on the 
appropriate qualitative training, attachment(3)

- In light of the results of the research, the following conclusions were reached

- The total time of the skill of Drop on the heel was (1.27 seconds) where the time of preliminary stage (hold and accumulation) was 0.22 and the percentage was $28.6 \%$, and the time of basic stage (shooting and implementation ) was 0.25 and the percentage was $32.4 \%$, and the final stage time (confinement) was 0.30 and the percentage was $39 \%$.

- Each of the right heel, hands, wrists, thighs and right knee was in the first phase from the fastest parts due to the nature of its work as it work to carry the player to lose his balance so that he loses his contact with the ground.

- The detente of knee angle results better work in the production of power, where all the muscles working around this joint have the opportunity to be mobile. This causes the movement transferring into the pelvic point, where the total power of the lower part during lifting up and forward acts.
Recommendations:

In light of the results of the current research, the researcher recommends the following:

- Note that it is not possible to separate the stages of the performance of the skill in question during performance, since the skill is an integrated unit that performs without fragmentation.- The Egyptian Wrestling Federation must pay attention to the results of the biomechanical research of the different skills of wrestling sport because they are very important in developing and improving the performance, to work on supplying the technical equipment responsible for the different national products with mechanical information about the method of skillful performance.

- Adherence to the technical aspects of the study qualitatively and quantitatively as a guide for the education, training and the regulation of loads.

- Using the results of this study in the preparation of training programs for young people and high levels.

\section{Assiut Journal For Sport Science Arts}




\section{References}

Arabic References:

1- Fawzi, E, M (2004):

Strategy for Training of the Skill of Back Throw through Kinetic Analysis, Published Research, the Scientific Journal Specialized in the Sciences of Physical Education and Sports (Theories and Applications), no.53, Faculty of Physical Education for Boys, University Alexandria.

2- Abdullah, H, J (2005): Determination of the Dynamic Characteristics of the Skill of the Back Throw against the Back for Wrestlers, Master, Faculty of Physical Education, Assiut University.

3- Mohammed, H, T (2006):

Kinetic Characteristics as an Indicator of the Development of the Great Technical Movement of Wrestling Players, Master Thesis, Faculty of Physical Education for Boys, Cairo, Helwan University.

4- Al-Said, I, A (1996): Effect of a Proposed Training Program for the Development of Dynamic Balance for Wrestlers under 14 Years, $\mathrm{PhD}$, Faculty of Physical Education, Suez Canal University, Port Said.
5- Al-Saied, I, A (2001):

Biomechanical Analysis of the Performance of Back Throw by Facing Skill, Published Research, the Scientific Journal of Research and Studies in Physical Education, No. 2, Faculty of Physical Education, Suez Canal University, Port Said.

6- Al-Saied, I, A \& Abdul Latif, M, S (2006): "Quantitative Change of some of the Biomechanical Amounts of the Skill of Encircling the Arm and Neck and Throwing from above the Bench in the Sport of Wrestling, Published Research, the Scientific Journal of Research and Studies in Physical Education, Suez Canal University.

7- Jafar, I, F (2004): the Mechanism of Moments Points Causing the Completion of the Skill of the High Beam as a Basis for Skillful and Physical Training in the Sport of Greek- Free Wrestling, Published Research, the Scientific Journal of Physical Education Sciences, No. 5, Faculty of Physical Education Tanta University.

8- Mustafa, I, F (2002): Dynamic Characteristics of the Stages of Teaching the Skill of 
Back Throw by Facing for Wrestlers, PhD, Faculty of Physical Education, Suez Canal University, in Port Said.

9- Mahmoud, M, A (2005): Encyclopedia of Free Wrestling for the Players, Book House and National Documentations, Cairo.

10-Tammam, O, A (2018): Analytical Study of the Dynamic Variables of the Double Leg Dive Skill as a Basic for Designing a Training Device for Free Wrestling Players, PhD, Faculty of Physical Education, Assiut University.

11- Abdel Aziz, O, M (2004): Dynamic Characteristics of the Skill of Back Throw by Facing in the Sport of Wrestling, Published Research, the Scientific Journal of the Sciences of Physical Education and Sports, the Fifth no., Faculty of Physical Education Tanta University.
12-Mohammed, T, A (2004): Relation of some Biomechanical Determinants of the Skill of the Arm Throw above the Back by the Performance Level for Wrestlers, Master Thesis, Faculty of Physical Education, Tanta University.

\section{Foreign References:}

13- Jung, T. \& Gucho, H., (2008): The contribution of lower limp segments by premovement in Taekwondo round House Kicking Yongin University, yongin City, Korea.

14- Ray parton., (1991): Specific exercises for athletes smith washing ton. 'publisher 15-Witt, K., et al., (2008): Biomechanical measuring stations to solve practical problems in karate sport department of sport science, Otto-von-Guericke- University, Magdeburg, Germany. 